\title{
A study on the kinetics of bismuth oxide reduction by hydrogen as applied to the technology of removing hydrogen from circulation circuits with heavy liquid metal coolants*
}

\author{
Igor I. Ivanov ${ }^{1}$, Vasily M. Shelemetyev ${ }^{1}$, Radomir Sh. Askhadullin ${ }^{1}$ \\ 1 JSC "SSC RF-IPPE" n.a. A.I. Leypunsky, 1, Bondarenko square, Obninsk, Kaluga region, 249033 Russia \\ Corresponding author: Igor I. Ivanov (iivanov@ippe.ru)
}

Academic editor: Boris Balakin • Received 3 September 2019 Accepted 10 November 2019 Published @ December 2019

Citation: Ivanov II, Shelemetyev VM, Askhadullin RSh (2019) A study on the kinetics of bismuth oxide reduction by hydrogen as applied to the technology of removing hydrogen from circulation circuits with heavy liquid metal coolants. Nuclear Energy and Technology 5(4): 331-336. https://doi.org/10.3897/nucet.5.48425

\begin{abstract}
As part of the project on developing methods for removing hydrogen and tritium from the circulation circuits of reactor plants with heavy liquid metal coolants, the authors studied the kinetics of bismuth oxide reduction by hydrogen in the temperature range of $425-500{ }^{\circ} \mathrm{C}$ and hydrogen concentrations of $25-100 \mathrm{vol} . \%$. The kinetic characteristics of the test reaction were determined by continuous measurements of the water steam (reaction product) concentration in mixtures of hydrogen with helium that passed through a heated reaction vessel with a sample of bismuth oxide. The water steam concentration was measured by a thermal-conductivity detector. The obtained time dependences of the bismuth oxide reduction degree (with varying reaction conditions) were processed by the affine time transformation method. It was also found that the reduction process ran in kinetic mode. The reduction mechanism is the same in the entire temperature range. The limiting reaction stage is the adsorption of hydrogen on the surface of the bismuth oxide sample. The time dependence of the reduction degree is in good agreement with Avrami-Erofeev equation with $n=1$. The reaction activation energy is $92.8 \pm 1.9 \mathrm{~kJ} / \mathrm{mol}$. The reduction reaction rate is directly proportional to the concentration of hydrogen in its mixture with an inert gas.
\end{abstract}

\section{Keywords}

Heavy liquid metal coolants (HLMC), nuclear safety, hydrogen, tritium, hydrogen purification of HLMC, hydrogen afterburner, bismuth oxide, reaction kinetics, thermal-conductivity analysis, affine time transformation method, Avrami-Erofeev equation.

\section{Introduction}

In recent decades, civil fast reactor plants with heavy liquid metal coolants (HLMC) based on lead and lead-bismuth eutectic (LBE) alloys have been intensely developed. Both lead and lead-bismuth alloys have a number of advantages as compared with other coolants for reactor plants, including, first of all, small fast neutron capture cross sections, relatively low melting points and high boiling points, and high thermal con-

* Russian text published: Izvestiya vuzov. Yadernaya Energetika (ISSN 0204-3327), 2019, n. 3, pp. 108-119. 
ductivity (Orlov et al. 2007, Handbook on Lead-Bismuth Eutectic Alloy 2007).

However, there are some difficulties associated with their use as coolants. One of the main problems is the interaction of these coolants with oxygen, which can enter the circulation circuit when the coolant is loaded or during operation in the presence of leaks (Ricapito et al. 2002, Niu et al. 2007). The interaction of HLMCs with oxygen results in the formation of lead oxide (Kondo et al. 2016), which, when excess oxygen is present (above the lead saturation line), forms slags, thereby impairing the coolant circulation and heat transfer in the core and steam generators.

To clean the circulation circuit from $\mathrm{PbO}$-based slags, a hydrogen regeneration method has been developed, which consists in feeding mixtures of hydrogen with an inert gas to the surface and into the coolant volume (Ricapito et al. 2002, Martynov et al. 2005). When hydrogen interacts with $\mathrm{PbO}$, lead is reduced from it, and the reaction product is water steam. The finely dispersed gas phase in the coolant flow provides a large area of interaction of the slags with hydrogen. As a result of the combined action of these two mechanisms, the circuit is effectively cleaned of the slags.

After hydrogen regeneration, a certain amount of hydrogen remains in the gas circuit. It can also accumulate in the circuit during leaks of the steam generators due to the interaction of incoming water steam with impurities dissolved in the coolant (primarily iron) (Martynov et al. 2005). As the recent experience (the accident at the Fukushima Daiichi NPP) has shown, hydrogen poses a serious security risk because it can explode when mixed with air (i.e., when the circuit is depressurized). In addition, when the primary circuit materials are irradiated, a radioactive isotope of hydrogen (tritium) is formed. Therefore, it is necessary to purify the protective gas of the primary circuit from hydrogen.

Based on the analysis of various methods for removing hydrogen from gaseous media, the specialists of the SSC RF-IPPE proposed purifying the protective gas from hydrogen by passing it through a special device containing heated $\mathrm{PbO}$ or $\mathrm{Bi}_{2} \mathrm{O}_{3}$ (Ivanov et al. 2013). It is advisable to use these substances, since, if they enter the coolant during an accident, they do not cause significant changes in its physicochemical properties. When interacting with $\mathrm{PbO}$ or $\mathrm{Bi}_{2} \mathrm{O}_{3}$, hydrogen is oxidized to form water, which is removed by condensation in the cold zone of the circuit.

To select the optimal operating conditions for the gas purifying device (including temperature, gas flow rate through the device, purification time), data are needed on the kinetics of the interaction of $\mathrm{PbO}$ and $\mathrm{Bi}_{2} \mathrm{O}_{3}$ with hydrogen.

The kinetics of $\mathrm{PbO}$ reduction by hydrogen was studied in our previous works (Ivanov et al. 2015, 2016). The kinetics of reducing bismuth from its oxide by hydrogen was also studied earlier in (Chernogorenko and Lynchak 1973, Beres et al. 1972). However, the data of these studies regarding the qualitative and quantitative characteristics of this process kinetics (the limiting reaction stage, activation energy) are very different, which makes the present study very relevant.

\section{Experimental procedure}

\subsection{Experimental technique}

The kinetics of reducing bismuth oxide samples by hydrogen was studied at the facility, the layout of which is shown in Fig. 1. The main components of the facility are a reaction chamber (1), a chromatograph (2), stainless steel gas lines (3), and a signal recording system (4). The right side of the reaction chamber is equipped with a heater (5); an alundum boat (6) for bismuth oxide samples and a piston (7) are located inside the chamber. A bismuth oxide sample was placed in a boat located in the left unheated part of the reaction chamber, then a stream of hydrogen from the cylinder (8) was passed through it with a constant flow rate of $50 \mathrm{ml} / \mathrm{min}$, and the right part of the chamber was heated to the operating temperature. Then with the help of the piston (7) the boat with the sample was moved to the right, heated part of the reaction chamber. The resulting mixture of hydrogen and water steam was fed via a heated gas line (3) to an LHM-80 chromatograph with a thermal conductivity detector (2), where its composition was determined. The signal recorded from the thermal conductivity detector is directly proportional to the water steam concentration in the gas.

During the experiments, the temperature in the reaction chamber was controlled by a chromel-alumel thermocouple with an accuracy of $\pm 1{ }^{\circ} \mathrm{C}$. Before the experiments, the thermocouple was calibrated over the entire studied temperature range; the deviation of the thermocouple readings from the true temperature did not exceed $2{ }^{\circ} \mathrm{C}$ and was taken into account in the calculations.

In the experiments, bismuth oxide was used in the form of a powder of the "pure for analysis" grade according to GOST 10216-75. The particle size ranged from a few micrometers to several tens of micrometers, the crystals had a compact shape. The degree of sample purity and the shape of sample crystals should be taken into account, since the kinetics of heterogeneous reactions very much depends on these parameters (Delmon 1972). The presence of moisture in the bismuth oxide sample led to the appearance of a peak in the initial portion of the recorded kinetic curve and significantly distorted the shape of this portion; therefore, before reduction, the bismuth oxide powder was calcined in an alundum crucible in a muffle furnace for $1 \mathrm{~h}$ at $500{ }^{\circ} \mathrm{C}$. According to (Risold et al. $1995)$, heating the $\alpha$-form of $\mathrm{Bi}_{2} \mathrm{O}_{3}$, which is the only one stable under normal conditions, at $500{ }^{\circ} \mathrm{C}$ both in an inert atmosphere and in air does not lead to a change in the composition and crystal structure of the sample. We found that during calcination the main part of moisture is removed from the sample, and the peak due to its presence is not recorded.

To determine the dependence of the bismuth oxide reduction rate on the volumetric hydrogen concentration in the gas, mixtures of hydrogen with helium, instead of 


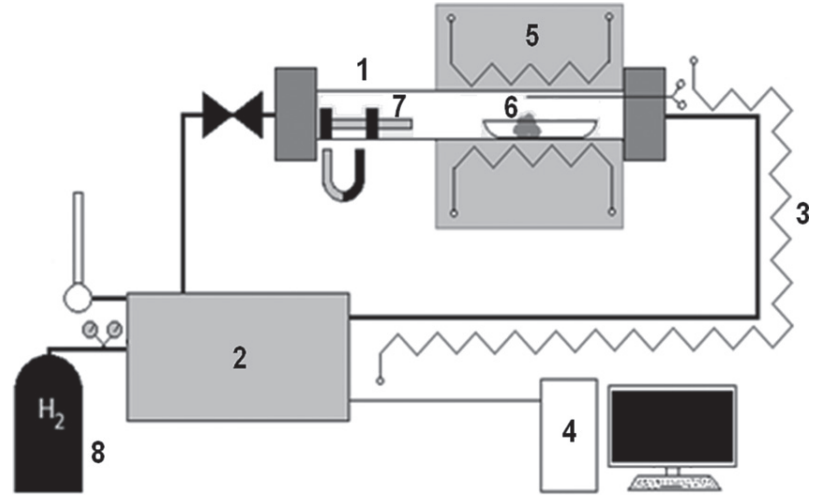

Figure 1. Facility for studying the kinetics of bismuth oxide reduction by hydrogen: 1 . Reaction chamber; 2 . Chromatograph; 3 . Heated gas line; 4. Signal recording unit; 5. Furnace; 6. Sample boat and a thermocouple; 7. Quartz piston; 8. Hydrogen cylinder.

pure hydrogen, were fed into the reaction chamber. Helium was chosen as an inert "diluent," since a thermal conductivity detector (built into the chromatograph) was used to analyze the moisture content in the gas passing through the reaction chamber; helium has a thermal conductivity close to that of hydrogen and, therefore, does not significantly affect the sensitivity of the detector and the linear dependence of the detector signal on the moisture content. Gases were supplied from cylinders with a constant flow rate through rotameters, mixed, and the resulting mixture of a required composition was supplied to the reaction vessel and to the reference channel of the thermal conductivity detector. The total gas flow rate through the reaction vessel in each experiment was 50 $\mathrm{ml} / \mathrm{min}$. The rotameters were calibrated over the entire range of gas flow rates $(0-50 \mathrm{ml} / \mathrm{min})$ against a foam flow meter. The error in determining the gas flow rate was $\pm 1 \mathrm{ml} / \mathrm{min}$.

\subsection{Methods for processing measurement results}

The considered reduction reaction of $\mathrm{Bi}_{2} \mathrm{O}_{3}$ by hydrogen is determined by the equation

$$
\mathrm{Bi}_{2} \mathrm{O}_{3}+3 \mathrm{H}_{2}=2 \mathrm{Bi}+3 \mathrm{H}_{2} \mathrm{O} \text {. }
$$

The main kinetic characteristic of the heterogeneous reaction under consideration is the time dependence of the degree of $\mathrm{Bi}_{2} \mathrm{O}_{3}$ reduction (kinetic curve). The degree of reduction $\alpha$ is equal to the percentage ratio of the mass of the reacted $\mathrm{Bi}_{2} \mathrm{O}_{3}$ to the initial mass of $\mathrm{Bi}_{2} \mathrm{O}_{3}$ :

$$
\alpha=100 \cdot m_{\mathrm{Bi}_{2} \mathrm{O}_{3}} / m_{\mathrm{Bi}_{2} \mathrm{O}_{3}}^{0} .
$$

As was already mentioned, the signal recorded from the thermal conductivity detector is directly proportional to the water steam concentration in the gas:

$$
I=h \cdot c_{\mathrm{H}_{2} \mathrm{O}},
$$

where $I$ is the detector current, $\mathrm{mA} ; c_{\mathrm{H} 2 \mathrm{O}}$ is the mass concentration of water steam, $\mathrm{g} / \mathrm{l} ; h$ is the proportional factor.

Multiplying the concentration of water steam by the gas flow rate through the facility $V(1 / h)$, we can obtain the rate of water formation $v_{\mathrm{H} 20}, \mathrm{~g} / \mathrm{h}$ :

$$
v_{\mathrm{H}_{2} \mathrm{O}}=I \cdot V / h .
$$

The mass of water released at time $t$ can be determined from the ratio

$$
m_{\mathrm{H}_{2} \mathrm{O}}(t)=\int_{0}^{t} \frac{V \cdot I(t)}{h} d t .
$$

In accordance with the stoichiometry of reaction (1), the mass of the reacted $\mathrm{Bi}_{2} \mathrm{O}_{3}$ is determined by the ratio

$$
m_{\mathrm{Bi}_{2} \mathrm{O}_{3}}(t)=M_{\mathrm{Bi}_{2} \mathrm{O}_{3}} \cdot m_{\mathrm{H}_{2} \mathrm{O}} /\left(3 \cdot M_{\mathrm{H}_{2} \mathrm{O}}\right),
$$

where $M_{\mathrm{Bi} 2 \mathrm{O} 3}$ and $M_{\mathrm{H} 2 \mathrm{O}}$ are the molar masses of $\mathrm{Bi}_{2} \mathrm{O}_{3}$ and water, respectively. By substituting (5) into (6), and taking into account (2), we can obtain an expression for the time dependence of the $\mathrm{Bi}_{2} \mathrm{O}_{3}$ reduction degree:

$$
\alpha(t)=100 \cdot M_{\mathrm{Bi}_{2} \mathrm{O}_{3}} \cdot \int_{0}^{t} \frac{V \cdot I(t)}{h} d t /\left(3 \cdot M_{\mathrm{H}_{2} \mathrm{O}} \cdot m_{\mathrm{Bi}_{2} \mathrm{O}_{3}}^{0}\right) .
$$

To compare the shapes of the kinetic curves as well as to determine the reaction activation energy and the dependence of the reaction rate on the partial pressure of hydrogen, the affine time transformation method was used (Ivanov et al. 2015, 2016). This method consists in changing the time scale for one of the time dependences of the reduction degree, leading to a combination with another time dependence of the reduction degree obtained under other conditions (at a different temperature or other partial pressure of hydrogen). The transformation occurs by multiplying the time $t$ in the kinetic curve equation by the affine transformation coefficient $f$. The value of the affine transformation coefficient for two kinetic curves at a given value of the reduction degree can be found by the formula

$$
f_{\alpha}=t_{1, \alpha} / t_{2, \alpha}
$$

where $\alpha$ is the reduction degree; $t_{i}$ is the time during which the reduction degree is achieved in the case of the $i$-th curve.

The values of the affine transformation coefficients for different reduction degrees may slightly differ, for example, due to the measurement error when the signal from the detector is recorded. It is possible to calculate the average value of the affine transformation coefficient for the two kinetic curves used in this paper:

$$
f=\int_{0}^{100} \frac{t_{1}(\alpha)}{t_{2}(\alpha)} d \alpha / 100 .
$$




\section{Experimental result}

\subsection{Reduction thermodynamics}

The Gibbs energy of reaction (1) is determined by the relation

$$
\Delta G_{m}^{0}=3 \Delta G_{m},{ }_{\mathrm{H}_{2} \mathrm{O}^{0}}-\Delta G_{m, \mathrm{Bi}_{2}, \mathrm{O}_{3}}^{0}+3 \cdot R \cdot T \cdot \ln \left(p_{\mathrm{H}_{0} \mathrm{O}} / p_{\mathrm{H}_{2}}\right),
$$

where $T$ is the temperature (in kelvins). According to ( $\mathrm{Ri}$ sold et al. 1995, Oniyama and Wahlbeck 1988), $\alpha-\mathrm{Bi}_{2} \mathrm{O}_{3}$ is a thermodynamically stable form of bismuth oxide in the studied temperature range $425-500{ }^{\circ} \mathrm{C}$; therefore, the Gibbs energy of the formation of this form of $\mathrm{Bi}_{2} \mathrm{O}_{3}$ was used in the calculations. Based on the data on the temperature dependences of the Gibbs energy of the formation of $\alpha-\mathrm{Bi}_{2} \mathrm{O}_{3}$ (Jacob and Mansoor 2016) and water (Wicks and Block 1963) from equation (10), the Gibbs energy of reaction (1) was calculated:

$$
\Delta G_{m}^{0}, \mathrm{~kJ} \cdot \mathrm{mol}^{-1}=-886.4-0.1278 \cdot T+3 \cdot R \cdot T \cdot \ln \left(p_{\mathrm{H}_{2} \mathrm{O}} / p_{\mathrm{H}_{2}}\right) .
$$

The criterion for establishing the thermodynamic equilibrium in the system is the equality of the Gibbs energy of the reaction to zero. Hence, using (11), we can obtain the criterion for establishing the equilibrium of reaction (1):

$$
p_{\mathrm{H}_{2} \mathrm{O}} / p_{\mathrm{H}_{2}}=\exp [(886.4+0.1278 \cdot T)] /(3 \cdot R \cdot T) .
$$

According to equation (12), the equilibrium ratio of partial pressures of water steam and hydrogen for reaction (1) is $2.23 \times 10^{24}$ at a temperature of $425{ }^{\circ} \mathrm{C}$ and $1.59 \times 10^{22}$ at $500{ }^{\circ} \mathrm{C}$. At lower values of this ratio, the Gibbs energy of reaction (1) takes a negative value and the reaction proceeds spontaneously. This is true for the experimental conditions of this work, since the maximum recorded partial pressure of the water steam formed during $\mathrm{Bi}_{2} \mathrm{O}_{3}$ reduction did not exceed 0.1 atm (at $500{ }^{\circ} \mathrm{C}$ and a hydrogen partial pressure of 1 atm at the initial moment of reduction), while the minimum created partial pressure of hydrogen was $0.26 \mathrm{~atm}$. The $\mathrm{Bi}_{2} \mathrm{O}_{3}$ reduction process should be complete, which is confirmed by direct measurement of the weight of the samples before and after the reduction reaction with an accuracy of $\pm 0.005 \mathrm{~g}$; the measurement showed that bismuth oxide was completely reduced to metallic bismuth in all experiments.

\subsection{Reduction kinetics}

First, it is necessary to consider the effect of the reduced $\mathrm{Bi}_{2} \mathrm{O}_{3}$ powder layer thickness and sample heating during the reduction reaction on the reaction rate. It was found that the powder layer thickness in the alundum boat does not affect the kinetics of the reduction process. Thus, a change in the sample weight from 0.25 to $1 \mathrm{~g}$, while the length and width of the powder layer is maintained (1.5 and $1.0 \mathrm{~cm}$, respectively), did not affect the shape of the time dependence of the reduction degree at a temperature of $500{ }^{\circ} \mathrm{C}$; therefore, it can be assumed that the stage of diffusion of the reagents (reaction products) through the powder layer does not limit the reaction rate (Barret 1975). It should be noted that the water steam generated during the $\mathrm{Bi}_{2} \mathrm{O}_{3}$ reduction reaction also does not affect the reaction rate, since, when the $\mathrm{Bi}_{2} \mathrm{O}_{3}$ sample weight changes, the amount of water steam released during the reaction changes, which, however, does not cause discrepancies in the shape of the kinetic curves obtained for the samples of different weights.

To determine the thermal effect of the reduction reaction on the sample temperature, $1 \mathrm{~g}$ of $\mathrm{Bi}_{2} \mathrm{O}_{3}$ was reduced by hydrogen at $500{ }^{\circ} \mathrm{C}$, and a thermocouple was placed in the center of the sample in a thin-walled alundum sheath. No deviations of the sample temperature from the furnace operating temperature were recorded, which allows us to consider the heat-release effect on the reaction rate to be negligible.

Figure 2 shows the time dependences of the $\mathrm{Bi}_{2} \mathrm{O}_{3}$ reduction degree obtained for various values of the reduction temperature. All the dependencies are combined with an affine time transformation for a reduction temperature of $425^{\circ} \mathrm{C}$; the plot also shows the equation of the approximating curve for this temperature. In the general case, the equation of the approximating curve has the form

$$
\alpha(t)=100 \cdot(1-\exp [-k \cdot t])
$$

where $k$ is the coefficient depending on the temperature, partial pressure of hydrogen, and qualitative characteristics of the $\mathrm{Bi}_{2} \mathrm{O}_{3}$ sample (specific surface, crystal surface structure).

Expression (13) formally corresponds to Avrami-Erofeev equation for the exponent $n=1$ (Allnatt and Jacobs 1968):

$$
\alpha(t)=100 \cdot\left(1-\exp \left[-k \cdot t^{n}\right]\right)
$$

It was noted in (Polyvyanny et al. 1973) that an equation similar to (13) approximately describes the kinetics of $\mathrm{Bi}_{2} \mathrm{O}_{3}$ reduction by carbon monoxide at the initial stage. In contrast to these data, a linear time dependence of $\mathrm{Bi}_{2} \mathrm{O}_{3}$ reduction by hydrogen was found in (Beres et al. 1972) for the temperature range of $350-500{ }^{\circ} \mathrm{C}$, but the reaction was carried out only to the reduction degree of $2-8 \%$.

The rate of the heterogeneous chemical reaction is directly proportional to the first time derivative of the reduction degree (Barret 1975). Differentiating equation (13) with respect to time, and taking into account (2), we find the expression for the dependence of the $\mathrm{Bi}_{2} \mathrm{O}_{3}$ reduction rate on the reduction time:

$$
v_{\mathrm{Bi}_{2} \mathrm{O}_{3}}(t)=m_{\mathrm{Bi}_{2} \mathrm{O}_{3}}^{0} \cdot k \cdot \exp [-k \cdot t],
$$

where $v_{B 12 \mathrm{O} 3}(t)$ is the $\mathrm{Bi}_{2} \mathrm{O}_{3}$ reduction rate, $\mathrm{g} / \mathrm{h}$. Thus, the $\mathrm{Bi}_{2} \mathrm{O}_{3}$ reduction rate and, in accordance with reaction equation (1), the rate of hydrogen removal from the protective gas decreases exponentially with time. The $k$ 


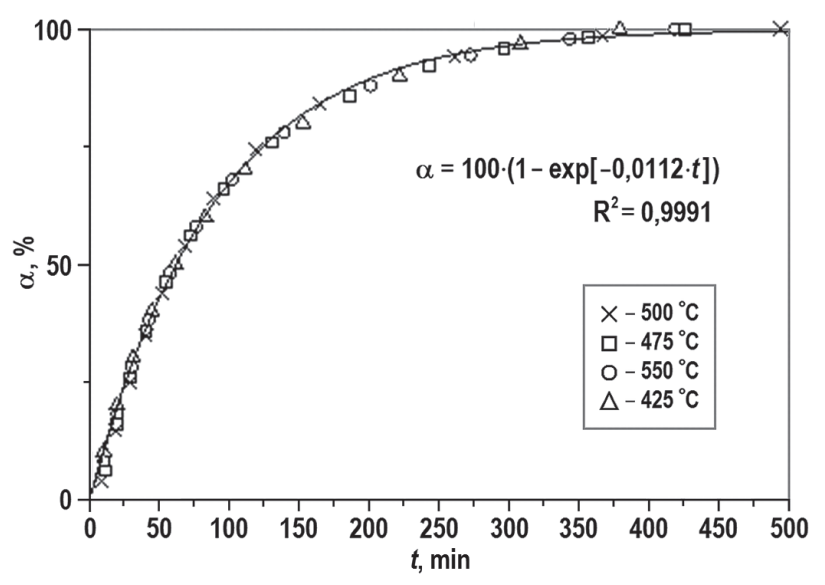

Figure 2. Time dependences of the $\mathrm{Bi}_{2} \mathrm{O}_{3}$ reduction degree obtained at various temperatures and combined by an affine time transformation with the dependence obtained at $425^{\circ} \mathrm{C}$. The solid line is the approximation of the obtained dependences by the exponential function $\left(\mathrm{R}^{2}\right.$ is the approximation confidence coefficient).

coefficient value for these reduction conditions can be determined by mathematical processing of the data, plotting the dependence $d \alpha / d t(\alpha)$. The slope of the obtained linear relationship is equal to the desired $k$ value.

A satisfactory combination of the kinetic curves during the affine time transformation suggests that the $\mathrm{Bi}_{2} \mathrm{O}_{3}$ reduction mechanism is the same in the entire studied temperature range (Barret 1975), and we can proceed to determine the reduction reaction activation energy. The activation energy was determined by the affine time transformation method, since the average value of the affine transformation coefficient is directly proportional to the $k$ coefficient of equations (13) and (15) (Ivanov et al. 2015, Barret 1975).

The logarithmic dependence of the affine transformation coefficient on the inverse temperature is shown in Fig. 3. The obtained activation energy value is 92.8 $\pm 1.9 \mathrm{~kJ} / \mathrm{mol}$. A close activation energy value was found in (Beres et al. 1972) $(90 \mathrm{~kJ} / \mathrm{mol})$. According to (Havlik 2008), when the process proceeds in kinetic mode, the activation energy assumes a value of more than $42 \mathrm{~kJ} / \mathrm{mol}$ and, therefore, it can be assumed that in the case of the reaction studied in this work the reduction also occurs in kinetic mode. The activation energy value found in (Chernogorenko and Lynchak 1973) for the range of reduction temperatures of $300-450{ }^{\circ} \mathrm{C}$ differs greatly from the values presented and is equal to $41.6 \mathrm{~kJ} / \mathrm{mol}$; the authors conclude that the reaction of bismuth oxide reduction by hydrogen proceeds in mixed mode. Based on the data obtained, we can write the equation for the temperature dependence of the $k$ coefficient as follows:

$$
k(T)=b \cdot \exp [-92800 /(R \cdot T)]
$$

where $b$ is the coefficient depending on the partial pressure of hydrogen in the gas, the specific surface area of the sample and the surface structure; $R$ is the universal gas constant; $T$ is the temperature (in kelvins).

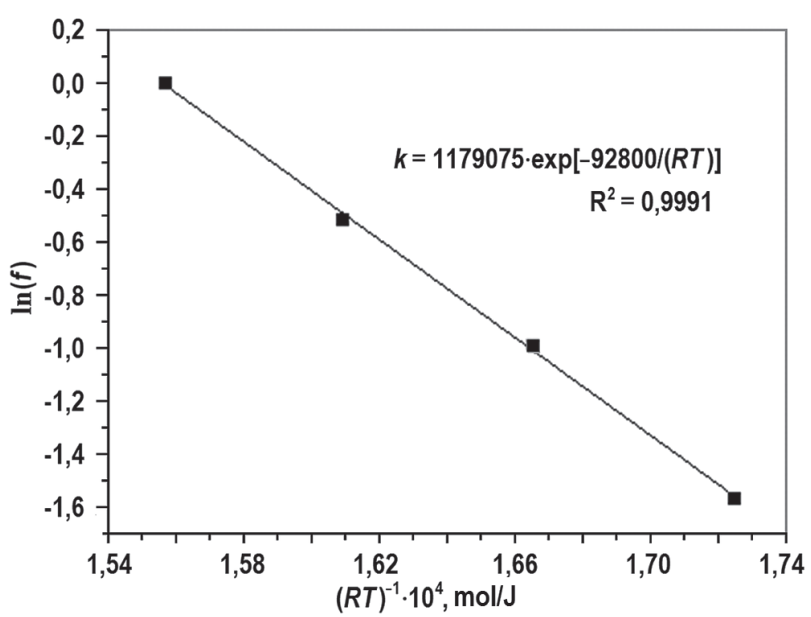

Figure 3. Dependence of $\ln (f)$ on $(R T)^{-1}$ for the bismuth oxide powder reduction by hydrogen. $T$ in kelvins $\left(\mathrm{R}^{2}\right.$ is the approximation confidence coefficient).

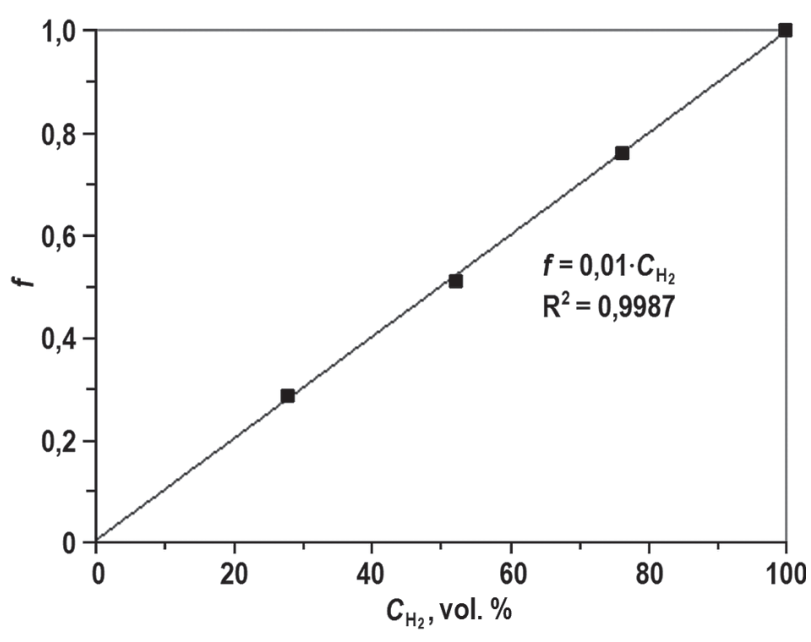

Figure 4. Dependence of the affine transformation coefficient $f$ on the volume concentration of hydrogen $C_{\mathrm{H} 2}$ at a bismuth oxide reduction temperature of $500{ }^{\circ} \mathrm{C}\left(\mathrm{R}^{2}\right.$ is the approximation confidence coefficient).

To determine the dependence of the bismuth oxide reduction rate on the hydrogen concentration in the gas, $\mathrm{Bi}_{2} \mathrm{O}_{3}$ was reduced by helium-hydrogen mixtures with a volumetric hydrogen content of $26,52,76$, and $100 \%$. The obtained time dependences of the reduction degree are satisfactorily combined with an affine time transformation.

The dependence of the reduction rate (i.e., the affine transformation coefficient proportional to it) on the volume concentration of hydrogen is well described by a straight line passing through the origin of coordinates (Fig. 4). Therefore, the reduction rate is directly proportional to the hydrogen concentration. Hence, we can write the following expression for the $b$ coefficient

$$
b=c \cdot p_{\mathrm{H}_{2}},
$$

where $c$ is the constant for a given $\mathrm{Bi}_{2} \mathrm{O}_{3}$ sample, depending on its specific surface and surface structure; it can be 
determined by calculating the $k$ coefficient for an arbitrary dependence $d \alpha / d t(\alpha)$ obtained at a temperature $T$ and a partial pressure of hydrogen $p_{\mathrm{H} 2}$, and using relations (16) and (17). Thus, using the value of $k=1.87 \cdot 10^{-4} \mathrm{~s}^{-1}$ found for $\mathrm{Bi}_{2} \mathrm{O}_{3}$ at a temperature of $425^{\circ} \mathrm{C}$ and $p_{\mathrm{H} 2}=100 \mathrm{kPa}$, we find $c=0.0164 \mathrm{~s}^{-1} \mathrm{~Pa}^{-1}$.

\section{Conclusion}

The authors studied the kinetics of bismuth oxide reduction by hydrogen. The activation energy of the reduction process is $92.8 \pm 1.9 \mathrm{~kJ} / \mathrm{mol}$, i.e., the reaction rate is highly dependent on temperature. Due to this, it is advisable to purify the gas of the circulation circuit from hydrogen at an elevated temperature of about $500{ }^{\circ} \mathrm{C}$. The time dependence of the bismuth oxide reduction degree is described by Avrami-Erofeev equation with a power factor $n=1$. The reduction rate linearly depends on the parti-
A dependence similar to equation (17) was found in (Chernogorenko and Lynchak 1973). The obtained dependence, in accordance with general ideas about the kinetics of heterogeneous processes (Barret 1975), indicates that the limiting reaction stage is the adsorption of hydrogen on the surface of $\mathrm{Bi}_{2} \mathrm{O}_{3}$.

al pressure of hydrogen in the gas. The resulting kinetic equation obtained by generalizing relations (13), (16) and (17) has the following form:

$$
\alpha\left(t, T, p_{\mathrm{H}_{2}}\right)=100\left\{1-\exp \left[-c \cdot p_{\mathrm{H}_{2}} \cdot \exp (-92800 /(R \cdot T)) \cdot t\right]\right\} .
$$

The obtained kinetic equation will be further used to calculate and optimize the device for purifying gas from hydrogen in a circulation circuit with heavy liquid metal coolants.

\section{References}

- Allnatt AR, Jacobs PWM (1968) Theory of nucleation in solid state reactions. Canadian Journal of Chemistry 46: 111-116. https://doi. org/10.1139/v68-021

- Barret P (1975) Reaction Kinetics in Heterogeneous Chemical Systems. Elsevier, Amsterdam, 399 pp.

- Beres J, Bruckman K, Haber J, Janas J (1972) Kinetics of reduction of bismuth molybdate catalysts in hydrogen. Bulltin de l'Academie Polonaise des sciences, serie des sciences chimiques 20: 813-819.

- Chernogorenko VB, Lynchak KA (1973) Production of bismuth powder by the reduction of bismuth oxide with a mixture of molecular and atomic hydrogen. Soviet Powder Metallurgy and Metal Ceramics 12(5): 360-362. https://doi.org/10.1007/BF00791258

- Delmon B (1972) Kinetics of Heterogeneous Reactions. Mir Publ., Moscow, 554 pp. [in Russian]

- Nuclear Energy Agency (2007) Handbook on Lead-Bismuth Eutectic Alloy and Lead Properties, Materials Compatibility, Thermal-hydraulics and Technologies. Nuclear Energy Agency, Paris, 691 pp.

- Havlik T (2008) Hydrometallurgy. Principles and Applications. Woodhead Publishing Ltd., Cambridge, 207 pp.

- Ivanov II, Shelemetyev VM, Ulyanov VV, Storozhenko AN, Skobeev DA (2016) Studies on nickel effect on kinetics of lead reduction from its oxide by hydrogen. Research Journal of Pharmaceutical, Biological and Chemical Sciences 7: 1700-1709.

- Ivanov II, Shelemetyev VM, Ulyanov VV, Teplyakov YuA (2015) The kinetics of the reduction of orthorhombic and tetragonal lead oxides to lead with hydrogen. Kinetics and Catalysis 56: 304-307. https://doi.org/10.1134/S0023158415030076

- Ivanov KD, Niyazov S-AS, Chyoporov RYu (2013) Selective removing of hydrogen and tritium from cover gas of nuclear facilities with heavy liquid metal coolants. Proc. of the $4^{\text {th }}$ International Conference on Heavy Liquid Metal Coolants in Nuclear Technologies. Vol. 2, SSC RF-IPPE Publ., Obninsk, 437-440. [in Russian]

- Jacob KT, Mansoor AK (2016) Gibbs energy of formation of bismuth (III) oxide. Thermochimica Acta 630: 90-96. https://doi. org/10.1016/j.tca.2016.02.006
Kondo M, Okubo N, Irisava E, Komatsu A, Ishikawa N, Tanaka T (2016) Oxidation characteristics of lead-alloy coolants in air ingress accident. Proc. of the $5^{\text {th }}$ International Symposium on Innovative Nuclear Energy Systems, INES-5 (Tokyo, Japan, October 31-November 2): 386-394. https://doi.org/10.1016/j.egypro.2017.09.473

- Martynov PN, Gulevich AV, Orlov YuI, Gulevsky VA (2005) Water and hydrogen in heavy liquid metal coolant technology. Progress in Nuclear Energy 47: 604-615. https://doi.org/10.1016/j.pnucene.2005.05.063

- Niu F, Candalino R, Li N (2007) Effect of oxygen on fouling behavior in lead-bismuth coolant systems. Journal of Nuclear Materials 366: 216-222. https://doi.org/10.1016/j.jnucmat.2007.01.223

- Oniyama E, Wahlbeck PG (1988) Phase equilibria in the bismuth-oxygen system. Journal of Physical Chemistry B. 102: 4418-4425. https://doi.org/10.1021/jp980166a

- Orlov YuI, Efanov AD, Martynov PN, Gulevsky VA, Papovyants AK, Levchenko YuD, Ulyanov VV (2007) Hydrodynamic problems of heavy liquid metal coolants technology in loop-type and mono-block-type reactor installations. Nuclear Engineering and Design 237: 1829-1837. https://doi.org/10.1016/j.nucengdes.2007.03.008

- Polyvyanny IR, Ablanova AD, Batyrbekova SA, Sysoyev LN (1973) Metallurgy of Bismuth. Nauka Publ., Alma-Ata, 193 pp. [in Russian]

- Ricapito I, Fazio C, Benamati G (2002) Preliminary studies on PbO reduction in liquid $\mathrm{Pb}-\mathrm{Bi}$ eutectic by flowing hydrogen. Journal of Nuclear Materials 301: 60-63. https://doi.org/10.1016/S00223115(01)00728-0

- Risold D, Hallstedt B, Gauckler LJ, Lukas HL, Fries SG (1995) The bismuth-oxygen system. Journal of Phase Equilibria 16: 223-234. https://doi.org/10.1007/BF02667306

- Wicks CE and Block FE (1963) Thermodynamic Properties of 65 Elements - their Oxides, Halides, Carbides and Nitrides. U.S. Govt. Print. Off., Washington, 240 pp. 